\title{
IMPLEMENTASI METODE SAW DALAM PENERIMAAN SISWA BARU PADA SMA NEGERI 16 MEDAN
}

\author{
Adil Setiawan \\ Jurusan Sistem Informasi, Fakultas Teknik dan Ilmu Komputer \\ Universitas Potensi Utama; Jln. K.L. Yos Sudarso Km. 6,5 No. 3A Tanjung Mulia - Medan \\ Adio165@gmail.com
}

\begin{abstract}
Acceptance of new students In public schools has always been the number 1 attraction, because the quality of a school is influenced by several things, one of which is the value of prestige against an unstoppable modernization, and one other due to the high accreditation value, as well as the source Competent teaching power. But in this case, to have a quality student resources it is necessary to select the acceptance of students. Similarly, for SMA Negeri 16 Medan which is one of the favorite state high school in marelan area, which is one area in the city of field. In fact quite a lot of prospective students who enroll in SMA Negeri 16 Medan who have high school grades, because the number of prospective students who register exceeds the capacity, the selection of student acceptance based on rankings SMP report cards, and written test only. From the existing problems sometimes there are prospective students who were excluded because they get enough test score when he has a non-academic achievement, and a good personality. Criteria other than academic value, and such as personality and non-academic values, should be used as criteria as well as to determine which students are truly eligible to receive using the SAW method. Non academic is an achievement beyond the academic field that a student has ever achieved. Interview test is an assessment of the personality of the prospective student will be in by the enrollment system. This SAW method serves as a tool of SMA Negeri 16 Medan in making decisions on the selection process of new admissions.
\end{abstract}

Keywords: Test, enrollment, SAW, New Student, SPK

\begin{abstract}
Abstrak
Penerimaan siswa baru Pada Sekolah negeri selalu menjadi daya tarik yang nomor 1, di karenakan Kualitas sebuah sekolah dipengaruhi oleh beberapa hal, salah satunya adalah Nilai gengsi terhadap sebuah moderenisasi yang tidak dapat dibendung, dan salah satu lainnya dikarenakan adanya nilai akreditasi yang tinggi, serta sumber daya pengajar yang berkompeten. Namun dalam hal ini, untuk memiliki sumber daya siswa yang berkualitas maka diperlukan adanya penyeleksian dalam penerimaan siswa. Begitu pula bagi SMA Negeri 16 Medan yang merupakan salah satu SMA negeri favorit di daerah marelan, yang merupakan salah satu daerah di kota medan. Pada kenyataannya cukup banyak calon siswa yang mendaftar pada SMA Negeri 16 Medan yang memiliki nilai rapor SMP yang tinggi, karena jumlah calon siswa yang mendaftar melebihi kapasitas, maka penyeleksian penerimaan siswa berdasarkan perangkingan nilai raport SMP, dan test tertulis saja. Dari permasalahan yang ada terkadang ada calon siswa yang tersisihkan karena memperoleh nilai test yang cukup padahal dia memiliki prestasi non akademik, dan kepribadian yang baik. Kriteria selain nilai akademik, dan seperti nilai kepribadian dan non akademik, seharusnya dapat dijadikan kriteria juga untuk menentukan siswa yang benar-benar layak diterima
\end{abstract}


dengan menggunakan metode SAW. Non akademik merupakan prestasi diluar bidang akademik yang pernah dicapai seorang siswa. Test wawancara merupakan penilaian terhadap kepribadian yang dimiliki calon siswa akan di oleh dengan sistem enrollment. Metode SAW ini berfungsi sebagai alat bantu SMA Negeri 16 Medan dalam mengambil keputusan pada proses seleksi penerimaan siswa baru.

Kata Kunci: Test, enrollment, SAW, Mahasiswa Baru, SPK

\section{PENDAHULUAN}

Penyelenggaraan seleksi Penerimaan Siswa Baru diadakan setiap tahun ajaran baru oleh pihak Sekolah dan melakukan seleksi guna mendaptkan calon siswa-siswi yang berkompetensi. Kebanyakan sekolah masih menggunakan cara manual dalam pelaksanaan penerimaan Mahasiswa baru. Calon Mahasiswa harus mendatangi SMA Negeri 16 Medan yang ingin dituju untuk mendaftarkan diri dan mengetahui segala informasinya. Proses seperti ini sering mengalami permasalahan, seperti pengolahan data yang memerlukan waktu relatif lama, sulitnya pihak Dinas Pendidikan mengupdete informasi pendaftaran secara cepat dan berkala, serta sulitnya calon siswa yang harus mendaftar lebih dari satu sekolah ketika dia tidak lulus dari sekolah sebelumnya. Untuk itu, proses penerimaan siswa baru yang lebih efektif dan efisien perlu diupayakan, yaitu melalui membangun sistem enrollment yang dimulai dari proses daftar, proses seleksi, dan pengumuman hasil seleksi secara online dan terpusat di Dinas Pendidikan. Seluruh calon siswa mendaftar dan memilih sekolah yang diinginkan secara online, kemudian dilakukan perangkingan oleh sistem berdasarkan kriteria yang di tentukan pihak sekolah. Dari hasil perangkingan tersebut akan diketahui calon siswa bisa lulus atau tidak ke sekolah tersebut, selanjutnya sistem akan memberikan rekomendasi sekolah baru bagi calon siswa yang tidak lulus seleksi dengan pemilihan jarak tempuh terdekat tempat domisili calon siswa ke sekolah.

Metode SAW ini dipilih karena mampu menyeleksi alternatif terbaik dari sejumlah alternatif, dalam hal ini alternatif yang dimaksudkan yaitu berdasarkan kriteria-kriteria yang ditentukan. Penelitian dilakukan dengan mencari nilai bobot untuk setiap atribut, kemudian dilakukan proses perankingan yang akan menentukan alternatif yang optimal, yaitu yang terbaik [1].

Alasan tersebut menjadikan pembuatan suatu model dalam pengambilan keputusan merupakan hal penting, sehingga keputusan yang diambil merupakan keputusan yang akurat, cermat dan tentu saja menguntungkan bagi yang bersangkutan. Model pengambilan keputusan yang ada dipakai adalah SAW (Simple Additive Weighting) dan masih banyak model lainya. Setiap model memiliki kelebihan dan kekurangannya masing- masing dan tingkat kesulitan yang bervariasi. Model ini berfungsi sebagai sistem pendukung pengambilan suatu keputusan. Kualitas sebuah sekolah dipengaruhi oleh beberapa hal, salah satunya adalah sumber daya manusia, yaitu siswa yang dimiliki sekolah tersebut. Untuk memiliki sumber daya siswa yang berkualitas maka diperlukan adanya penyeleksian dalam peneriamaan siswa di 
sebuah sekolah. Seleksi penerimaan siswa baru merupakan agenda rutin tahunan bagi sebuah sekolah. Dengan semakin berkembangnya jaman dan pertumbuhan penduduk dari tahun ke tahun, membuat semakin tinggi pula calon siswa yang mendaftarkan diri disebuah sekolah. Namun keterbatasan fasilitas, sarana, dan prasarana sebuah sekolah terkadang sekolah tidak dapat menampung semua calon siswa yang mendaftar.

\section{METODOLOGI PENELITIAN}

\subsection{Sistem Komputer}

Menurut Janner dalam Elistri [2] Komputer secara umum adalah Sekelompok elemen-elemen yang saling berinteraksi dengan maksud yang sama untuk mencapai tujuan tertentu, dan juga Komputer merupakan suatu jaringan yang saling berhubungan, berkumpul, bersama-sama untuk melakukan suatu kegiatan tertentu.[2]

\subsection{Pengertian Sistem}

Menurut Muhammad Ardiansyah damanik[3], Sistem adalah Suatu kesatuan prosedur atau komponen yang saling berkaitan satu dengan yang lainnya, bekerja bersama-sama sesuai dengan aturan yang diterapkan sehingga membentuk suatu tujuan yang sama, di mana dalam sebuah sistem bila terjadi satu bagian saja yang tidak bekerja atau rusak maka suatu tujuan bisa terjadi kesalahan hasilnya atau outputnya [3].

Sistem adalah suatu jaringan kerja dari prosedur-prosedur yang saling berhubungan, berkumpul bersama-sama untuk melakukan suatu kegiatan atau untuk menyelesaikan suatu sasaran yang tertentu [4].

\subsection{Pengertian Sistem Pendukung Keputusan}

Sistem Pendukung Keputusan atau DSS (Decision Support System) adalah sistem informasi berbasis komputer yang tujuan utamanya adalah membantu pembuatan keputusan memanfaatkan data dan model untuk menyelesaikan masalah-masalah yang bersifat tidak terstruktur dan semi terstruktur [5]

Menurut Alter dalam buku [6], Sistem pendukung keputusan merupakan sistem informasi interaktif yang menyediakan informasi, pemodelan, dan pemanipulasian data di mana sistem yang digunakan untuk membantu pengambilan keputusan dalam situasi yang semiterstruktur dan situasi yang tidak terstruktur.

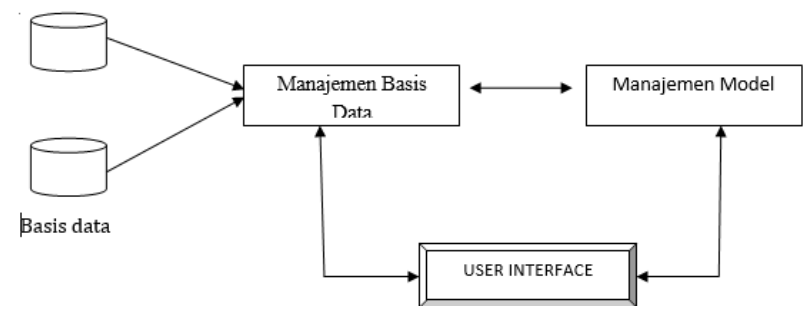

Gambar 1. Konseptual SPK 


\subsection{Arsitektur Sistem Pendukung Keputusan}

Aplikasi sistem pendukung keputusan bisa terdiri dari beberapa subsistem, yaitu :

1. Subsistem manajemen data

Subsistem manajemen data memasukan database yang berisi data yang relevan untuk suatu situasi dan dikelola oleh perangkat lunak yang disebut sistem manajemen database (DBMS). Subsistem manajemen data bisa diinterkoneksikan dengan data warehouse perusahaan, suatu repositori untuk data perusahaan yang relevan dengan pengambilan keputusan.

2. Subsistem manajemen modal

Merupakan paket perangkat lunak yang memasukkan model keuangan, statistik, ilmu manajemen, atau model kuantitatif lain yang memberikan kapabilitas analitik dan manajemen perangkat lunak yang tepat. Bahasabahasa pemodelan untuk membangun model-model kustom juga dimasukan.

3. Subsistem antarmuka pengguna

Pengguna berkomunikasi dengan dan memerintahkan sistem pendukung keputusan melalui subsistem tersebut. Para peneliti menegaskan bahwa beberapa kontribusi unik dari sistem pendukung keputusan berasal dari interaksi yang intensif antara komputer dan pembuat keputusan.

4. Subsistem manajemen berbasis pengetahuan.

Subsistem tersebut mendukung semua subsistem lain atau bertindak langsung sebagai suatu komponen independen dan bersifat opsional. Selain memberikan intelegensi untuk memperbesar pengetahuan sipengambil keputusan, subsistem tersebut bisa diinterkoneksikan dengan repositori pengetahuan perusahaan [6].

\subsection{Metode Simple Additive Weighting (SAW)}

Metode SAW adalah metode penjumlahan terbobot. Konsep dasar dari metode SAW adalah mencari penjumlahan terbobot dari rating kinerja pada setiap alternatif pada semua atribut.Metode SAW membutuhkan proses normalisasi matrik keputusan (X) ke skala yang dapat diperbandingkan dengan semua rating alternative yang ada [7]

Jika $\mathrm{j}$ adalah atribut keuntungan(benetif) Jika $\mathrm{j}$ adalah atribut biaya (cost):

dimana

$$
R i j=\left\{\begin{array}{c}
\frac{x i j}{\max x i j} \\
i \quad \\
\operatorname{Min} x i j \\
\frac{i}{x i j}
\end{array}\right.
$$

rij $\quad=$ Rating kinerja ternormalisasi

Max $\quad=$ Nilai maksimum dari setiap baris dan kolom

Min $=$ Nilai minimum dari setiap baris dan kolom

Xij $\quad=$ Bari dan kolom dari matrik. 


$$
V i=\sum_{j=1}^{n} w_{j} r_{i j}
$$

Dimana $r$ adalah ranting kinerja terkomputerisasi dari alternative $A_{i}$ pada atribut $C_{j} ; i$ $=1,2, \ldots, \mathrm{m}$ dan $\mathrm{j}=1,2, \ldots, \mathrm{n}$ Nilai preferensi untuk setiap alternative $\left(\mathrm{V}_{\mathrm{i}}\right)$ diberikan sebagai Nilai $\mathrm{V}_{i}$ yang lebih besar mengidentifikasikan bahwa alternative $\mathrm{A}_{\mathrm{i}}$ lebih terpilih.

Langkah-langkah dalam menentukan metode SAW:

a. Menentukan Kriteria yang akan dijadikan acuan dalam pengambilan keputusan, misalnya C1.

b. Menentukan rating kecocokan setiap alternatif pada setiap kriteria

c. Membuat matriks keputusan berdasarkan krite- ria (C1), kemudian melakukan normalisasi matriks berdasarkan persamaan yang disesuaikan dengan jenis atribut (atribut keun- tungan ataupun atribut biaya) sehingga matriks ternormalisasi R.

d. Hasil akhir diperoleh dari proses perankingan yaitu perjumlahan dari perkalian matriks ternor-malisasi $\mathrm{R}$ dengan vector bobot preferensi sehingga diperoleh nilai terbesar yang dipilih sebagai alternatif terbaik misalnya (A1).

\section{HASIL DAN PEMBAHASAN}

Pada SMA Negeri 16 Medan merupakan salah satu sekolah Negeri yang dalam proses penerimaan siswa baru di setiap tahunnya mengalami peningkatan, sehingga tidak dapat menampung semua calon siswa yang mendaftar pada SMA Negeri 16 Medan. Penyeleksian Penerimaan calon siswa ditentukan berdasarkan 4 (empat) kriteria, antara lain :
a. Nilai rapor
b. Nilai UN(Ujian Nasional)
c. Test Tertulis
d. Tes wawancara

Tabel 1. Bobot preferensi

\begin{tabular}{|l|l|l|}
\hline Nama criteria & Nilai bobot & Keterangan \\
\hline Nilai raport & 30 & C1 \\
\hline Nilai UN(Ujian Nasional) & 25 & C2 \\
\hline Test tertulis & 20 & C3 \\
\hline Test wawancara & 25 & C4 \\
\hline
\end{tabular}

\subsection{Perhitungan SAW Untuk Seleksi}

Penerimaan Siswa Baru Berikut perhitungan manual berdasarkan contoh kasus. Diambil tiga sample calon siswa dengan data sebagai berikut:

a. Sampel Nilai Calon Siswa 
Tabel 2. Sampel Nilai Calon Siswa

\begin{tabular}{|l|l|l|l|l|}
\hline \multirow{2}{*}{ Alternatif } & \multicolumn{4}{|c|}{ Kriteria } \\
\cline { 2 - 5 } & $\begin{array}{l}\text { Nilai } \\
\text { raport } \\
\text { (C1) }\end{array}$ & Nilai UN (C2) & $\begin{array}{l}\text { Nilai test } \\
\text { tertulis } \\
\text { (C3) }\end{array}$ & $\begin{array}{l}\text { Nilai tes } \\
\text { wawancara } \\
\text { (C4) }\end{array}$ \\
\hline Anton & 95 & 70 & 50 & 70 \\
\hline Rendi & 80 & 70 & 85 & 80 \\
\hline Siska & 80 & 60 & 80 & 80 \\
\hline Daniel & 70 & 40 & 80 & 78 \\
\hline
\end{tabular}

b. Rating kecocokan dari setiap alternative pada setiap kriteria

Tabel 3. Rating Kecocokan dari setiap alternative pada setiap kriteria

\begin{tabular}{|l|l|l|l|l|}
\hline \multirow{2}{*}{ Alternatif } & \multicolumn{4}{|c|}{ Kriteria } \\
\cline { 2 - 5 } & \multicolumn{1}{|c|}{ C1 } & \multicolumn{1}{c|}{ C2 } & \multicolumn{1}{c|}{ C3 } & C4 \\
\hline Anton & 95 & 70 & 50 & 70 \\
\hline Rendi & 80 & 70 & 85 & 80 \\
\hline Siska & 80 & 60 & 80 & 80 \\
\hline Daniel & 70 & 40 & 80 & 78 \\
\hline
\end{tabular}

c. Matrik keputusan dari tabel rating

kecocokan dari setiap alternative pada setiap kriteria. Pengambil keputusan memberikan nilai alternatif, berdasarkan tingkat kepentingan masing-masing kriteria yang dibutuhkan sebagai berikut: Vektor bobot $[W]=\{30,25,20,25\}$ membuat matriks keputusan X, dibuat dari tabel kecocokan sebagai berikut:

$\begin{array}{cccc}X=95 & 70 & 50 & 70 \\ 80 & 70 & 85 & 80 \\ 80 & 60 & 80 & 80 \\ 70 & 40 & 80 & 78\end{array}$

d. Normalisasi matrik keputusan Melakukan normalisasi matriks Dengan cara menghitung nilai rating siswa ternormalisasi (rij) dari altenatif Ai pada atribut $\mathrm{Cj}$ berdasarkan persamaan yang disesuaikan dengan jenis atribut (atribut keuntungan $/$ benefit $=$ MAKSIMUM atau atribut biaya $/ \operatorname{cost}=$ MINIMUM). Apabila berupa atribut keuntungan maka nilai crisp (Xij) dari setiap kolom atribut dibagi dengan nilai crisp MAX (MAX Xij) dari tiap kolom, sedangkan untuk atribut biaya nilai crisp MIN (Xij) dari tiap kolom.
$\mathrm{Rij}=\frac{x i j}{\frac{\min x i j}{x i j}}$
jika j adalah atribut keuntungan
jika j adalah atribut biaya (cost) 
Dengan cara menghitung nilai rating penilaian siswa ternormalisasi (rij) berdasarkan persamaan yang disesuaikan dengan jenis kriteria. Untuk semua kriteria ini menggunakan kriteria keuntungan (benefit).

1. Calon siswa Anton

$\mathrm{R} 11=\mathrm{x} 11 \frac{x 11}{\operatorname{maxi}(x 11, x 21, x 31)}=\frac{95}{\operatorname{maxi}(95,80,80,70)}=\frac{95}{95}=1,00$
$\mathrm{R} 12=\mathrm{x} 12 \frac{x 12}{\operatorname{maxi}(x 12, x 22, x 32)}=\frac{80}{\operatorname{maxi}(80,70,60,40)}=\frac{80}{80}=1,00$
$\mathrm{R} 13=\mathrm{x} 13 \frac{x 13}{\operatorname{maxi}(x 13, x 23, x 33)}=\frac{50}{\operatorname{maxi}(50,85,80,80)}=\frac{50}{85}=0,58$
$\mathrm{R} 14=\mathrm{x} 14 \frac{x 14}{\operatorname{maxi}(x 14, x 24, x 34)}=\frac{70}{\operatorname{maxi}(70,80,80,78)}=\frac{70}{80}=0,87$

\section{Calon siswa Rendi}

$\mathrm{R} 11=\mathrm{x} 11 \frac{x 11}{\operatorname{maxi}(x 11, x 21, x 31)}=\frac{80}{\operatorname{maxi}(95,80,80,70)}=\frac{80}{95}=0,84$
$\mathrm{R} 12=\mathrm{x} 12 \frac{x 12}{\operatorname{maxi}(x 12, x 22, x 32)}=\frac{70}{\operatorname{maxi}(80,70,60,40)}=\frac{70}{80}=0,87$
$\mathrm{R} 13=\mathrm{x} 13 \frac{x 13}{\operatorname{maxi}(x 13, x 23, x 33)}=\frac{85}{\operatorname{maxi}(50,85,80,80)}=\frac{85}{85}=1,00$
$\mathrm{R} 14=\mathrm{x} 14 \frac{\frac{x 14}{\operatorname{maxi}(x 14, x 24, x 34)}}{\operatorname{maxi}(70,80,80,78)}=\frac{80}{80}=1,00$

\section{Calon siswa Siska}

$\mathrm{R} 11=\mathrm{x} 11 \frac{x 11}{\operatorname{maxi}(x 11, x 21, x 31)}=\frac{80}{\operatorname{maxi}(95,80,80,70)}=\frac{80}{95}=0,84$

$\mathrm{R} 12=\mathrm{x} 12 \frac{x 12}{\operatorname{maxi}(x 12, x 22, x 32)}=\frac{60}{\operatorname{maxi}(80,70,60,40)}=\frac{60}{80}=0,75$

$\mathrm{R} 13=\mathrm{x} 13 \frac{x 13}{\operatorname{maxi}(x 13, x 23, x 33)}=\frac{80}{\operatorname{maxi}(50,85,80,80)}=\frac{80}{85}=0,94$

$\mathrm{R} 14=\mathrm{x} 14 \frac{x 14}{\operatorname{maxi}(x 14, x 24, x 34)}=\frac{80}{\operatorname{maxi}(70,80,80,78)}=\frac{80}{80}=1,00$

\section{Calon siswa Daniel}

$$
\begin{aligned}
& \mathrm{R} 11=\mathrm{x} 11 \frac{x 11}{\operatorname{maxi}(x 11, x 21, x 31)}=\frac{70}{\operatorname{maxi}(95,80,80,70)}=\frac{70}{95}=0,73 \\
& \mathrm{R} 12=\mathrm{x} 12 \frac{x 12}{\operatorname{maxi}(x 12, x 22, x 32)}=\frac{40}{\operatorname{maxi}(80,70,60,40)}=\frac{40}{80}=0,50 \\
& \mathrm{R} 13=\mathrm{x} 13 \frac{x 13}{\operatorname{maxi}(x 13, x 23, x 33)}=\frac{80}{\operatorname{maxi}(50,85,80,80)}=\frac{80}{85}=0,94 \\
& \mathrm{R} 14=\mathrm{x} 14 \frac{x 14}{\operatorname{maxi}(x 14, x 24, x 34)}=\frac{78}{\operatorname{maxi}(70,80,80,78)}=\frac{78}{80}=0,97
\end{aligned}
$$

e. Matrik ternomalisasi

Hasil dari nilai rating kinerja ternormalisasi akan membentuk matrik ternormalisasi.

$$
\begin{array}{cccc}
\mathrm{R}=1.00 & 1.00 & 0,58 & 0.87 \\
0,84 & 0,87 & 1.00 & 1.00 \\
0,84 & 0,75 & 0,94 & 1,00 \\
0,73 & 0,50 & 0,94 & 0,97
\end{array}
$$


f. Nilai preferensi

Dalam nilai preferensi didapat dari setiap alternatif (Vi) dijumlahkan dengan hasil kali antara matriks ternormalsasi (R) dengan nilai bobot (W). Nilai preferensi dari setiap alternatif calon siswa adalah sebagai berikut :

$\mathrm{V} 1=(1.00) \cdot(30)+(1.00) \cdot(25)+(0.58) \cdot(20)+(0.87) \cdot(25)\}=88,33$

$\mathrm{V} 2=(0,84) \cdot(30)+(0,87) \cdot(25)+(1.00) \cdot(20)+(1.00) \cdot(25)\}=91.95$

$\mathrm{V} 3=(0,84) \cdot(30)+(0.75) \cdot(25)+(0.94) \cdot(20)+(1.00) \cdot(25)\}=87 \cdot 25$

$\mathrm{V} 4=(0,73) \cdot(30)+(0,50) \cdot(25)+(0.94) \cdot(20)+(0.97) \cdot(25)\}=77,45$

Nilai terpilih ada pada V1,V2,V3 adalah rekomendasi alternatif yang terpilih sebagai alternatif terbaik Jika Kuota siswa 3, jika kuota data siswa 2 yang dipilih adalah V1 dan V2 saja, data disiapkan berdasarkan pada kebutuhan sistem. Serta dengan demikian maka data siswa yang gaga akan segera diarahkan pada sekolah-sekolah yang dekat dengan sekolah SMA negeri 16 medan.

\section{SIMPULAN}

Dari hasil pengujian dan implementasi sistem yang telah dilakukan, dapat disimpulkan bahwa :

a. Perhitungan pada system ini diharapkan dapat membantu dalam mendukung keputusan penerimaan siswa baru, pada SMA Negeri 16 Medan karena dapat memberikan informasi yang cepat, mudah, dan efisien.

b. Dengan menggunakan metode SAW (Simple Additive Weighting) dengan mencari penjumlahan terbobot dari kinerja pada setiap alternatif pada semua atribut. Sehingga memudahkan melihat hasil dari analisa sistem ini akan dapat berguna bagi pihak sekolah sebagai saran dalam melakukan pengambilan keputusan.

c. Pada siswa yang gagal maka akan segera di arahkan ke sekolah- sekolah terdekat di wilayah yang dekat dengan rumah siswa, pendataan penilaian, dan pendataan analisa. Pada hasil laporan yang diberikan yaitu laporan siswa berupa hasil perhitungan, sebagai saran bagi pihak sekolah untuk dapat meluluskan siswa yang akan bergabung di sekolah tersebut.

\section{DAFTAR PUSTRAKA}

[1] Henry Wibowo, dkk, 2009, "Sistem Pendukung Keputusan Untuk Menentukan Penerima Biasiswa Bank BRI Menggunakan FMADM",Yokyakarta, Seminar Nasional Aplikasi Teknologi Informasi

[2] Melisa, Elistri. dkk, 2014, "PENERAPAN METODE SAW DALAM SISTEM PENDUKUNG KEPUTUSAN PEMILIHAN JURUSAN PADA SEKOLAH MENENGAH ATAS NEGERI 8 SELUMA", Jurnal Media Infotama, Vol.10. No. 02

[3] Muhamad Ardiansah, (2013). "Sistem Pendukung Keputusan Pemindahan Tugas KaryawanDengan Menggunakan Metode Profile Matching" Vol 4, No.2. 
[4] Nur, dkk, (2009). "Sistem Pendukung Keputusan Perencanaan Strategis Kinerja Instansi Pemerintah Menggunakan Metode AHP". Vol 3, No.2.

[5] Arif, dkk, (2013). "Sistem Pendukung Keputusan Evaluasi Kinerja Karyawan Untuk Promosi Jabatan Struktural Pada Bimbingan Belajar Sciencemaster Menggunakan Metode Profile Matching”. Vol 5. No.2.

[6] Kusrini, 2007. "Konsep dan Aplikasi Sistem Pendukung Keputusan”. Penerbit Andi, Yogyakarta

[7] Kusumadewi, dkk, 2006, "Fuzzy Multi-Attribute Decision Making", Yogyakarta, Graha Ilmu. $361 \mathrm{Hal}$ 